\title{
DISCUSSION
}

\section{A unique relationship for $\chi$ for the determination of the shear strength of unsaturated soils}

\author{
N. KHALILI and M. H. KHABBAZ, (1998). Géotechnique 48, No. 5, 681-687
}

\section{Z. Cabarkapa, T. Cuccovillo and M. Gunn. South Bank} University, London

The main need of an engineer who is considering the stability of a geotechnical structure or a slope in unsaturated soil is for a simple and reliable estimate of the shear strength of the ground. The paper appears to provide an attractive approach to obtaining shear strength even if the writers believe that unsaturated soil behaviour can be better understood and described by keeping the mean net stress and suction as independent variables.

Our main concern about the authors' work is whether the relationship they propose can provide reliable estimates of shear strength. The relationship requires a knowledge of the two shear strength parameters $c^{\prime}$ and $\phi^{\prime}$ for the soil when fully saturated. It is well documented that the values of $c^{\prime}$ and $\phi^{\prime}$ vary with the state of the soil as defined by its density and the applied effective stresses (e.g. Wood, 1990). Unless the state of the saturated soil to which one should refer is specified, the choice of the two strength parameters in the proposed relationship remains arbitrary and, as such, cannot uniquely define the shear strength of the unsaturated soil. This aspect appears to be overlooked by the authors, who quote only fixed values of $c^{\prime}$ and $\phi^{\prime}$ for the soils considered.

Using the Hvorslev approach it is possible to fix the value of $\phi^{\prime}$ and estimate a value of $c^{\prime}$, but this involves a process of normalisation that requires a knowledge of the in-situ preconsolidation pressure of the soil if it was saturated. Even if this approach would produce single values of $c^{\prime}$ and $\phi^{\prime}$ for a given soil, it should still be verified whether these values would provide the correct shear strength of the unsaturated soil when used in the relationship proposed by the authors.

Another aspect to consider is that the shear strength parameters found with the Hvorslev approach will not be valid for low effective stress, where it would be better to use a curved failure envelope with a zero intercept. To describe the failure envelope over the whole stress range either a power function (Atkinson \& Farrar, 1985) or a hyperbolic function (Maksimovic, 1996) have been suggested. The hyperbolic function for the shear strength is given by

$$
\tau_{f}=\sigma_{n}^{\prime} \tan \left(\phi_{B}^{\prime}+\frac{\Delta \phi^{\prime}}{1+\sigma_{B}^{\prime} / P_{N}}\right)
$$

and has been used here to show how the variation of $c^{\prime}$ and $\phi^{\prime}$ with stress level influences the shear strength of the unsaturated soil calculated from the relationship proposed in the paper. The parameters appearing in equation (1) are defined in Fig. 6(a). Fig. $6(b, c)$ also shows the non-linear failure envelopes that fit the authors' data in terms of Mohr's circles (Khalili, personal communication, 1998) for the two saturated soils they considered. On the basis of these envelopes the parameters from the saturated soil have been derived and used to calculate the shear strength of the unsaturated soil from the suggested relationship. In Fig. 7 these calculated values are compared with those presented by the authors. It can be seen that by considering different values of $c^{\prime}$ and $\phi^{\prime}$ the shear strength can be underestimated by between $2 \%$ and $50 \%$ for the kaolin and between $15 \%$ and $45 \%$ for the sand-kaolin mixture, depending on the suction level.

The writers agree that the testing of unsaturated soils is time

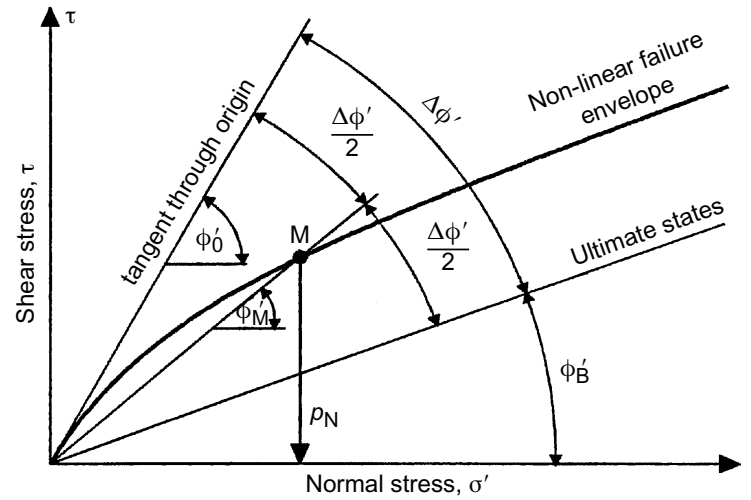

(a)

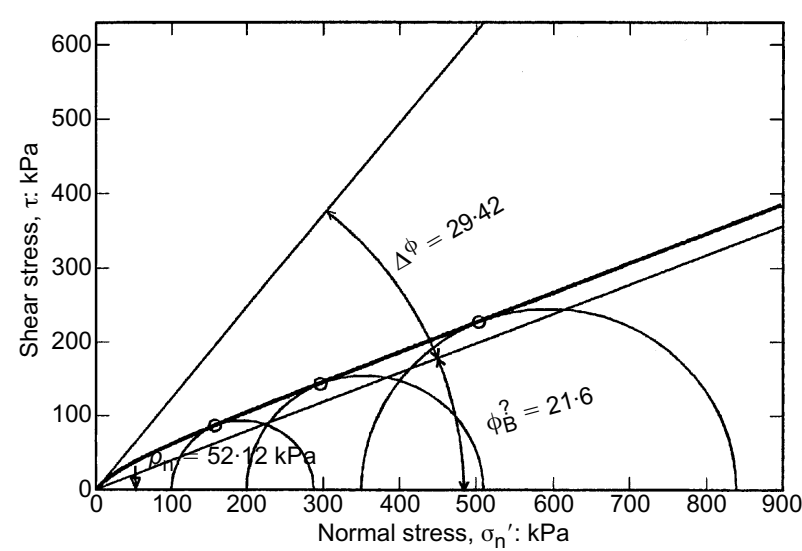

(b)

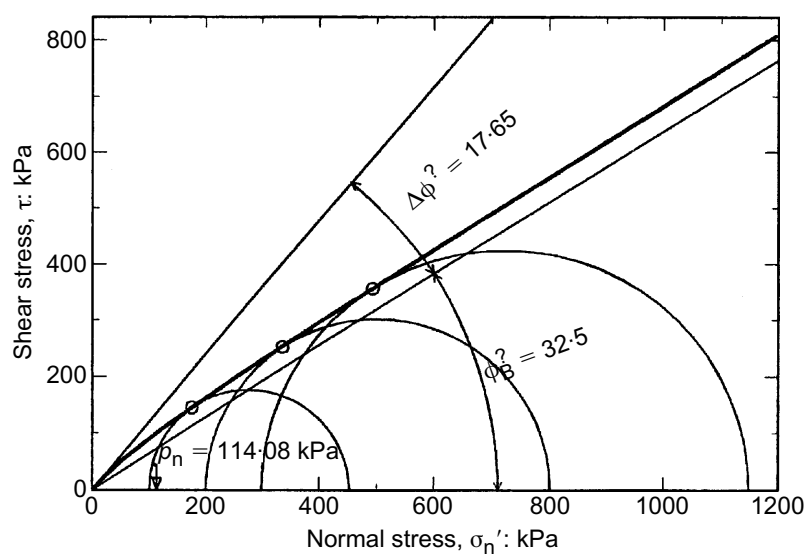

(c)

Fig. 6. Non-linear failure envelope: (a) schematic diagram defining strength parameters; (b) interpretation of test result for compacted kaolin; (c) interpretation of test result for compacted sand-clay mixture 


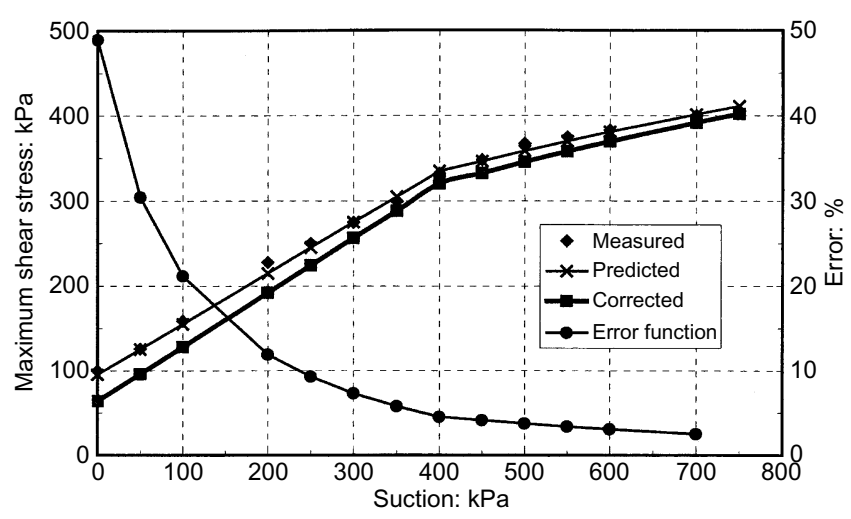

(a)

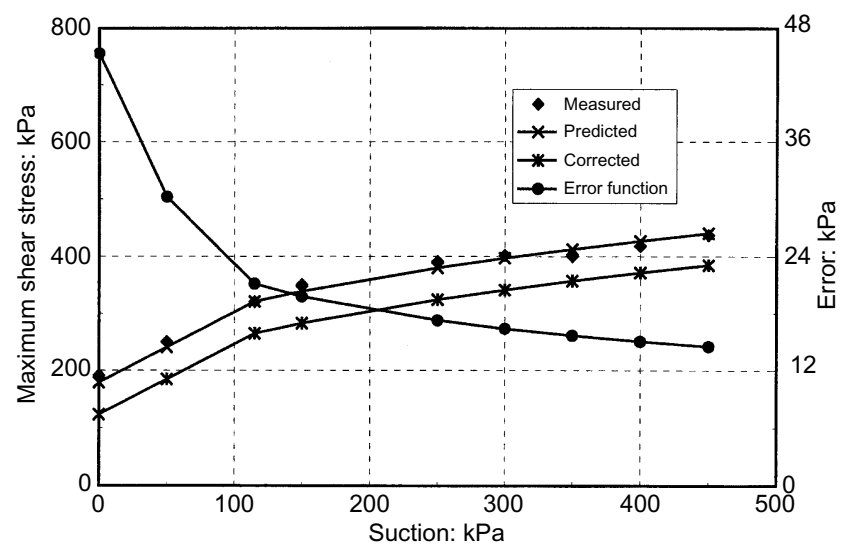

(b)

Fig. 7. Shear strength of unsaturated soil presented by the authors compared with values calculated using the non-linear failure envelope parameters for (a) compacted kaolin, (b) compacted sand-clay mixture consuming, but they disagree that the additional pieces of equipment required for unsaturated soil testing significantly increase the overall cost of a triaxial apparatus, which in their experience (Cabarkapa et al., 1998) has been found to be in the order of $20 \%$ greater than the standard case. In conclusion it appears that the accurate testing of unsaturated soil remains the only viable and reliable means by which it is possible to gain a fundamental understanding and a generalised formulation of models for the prediction of their behaviour.

\section{Author's reply}

To take into account the dependence of the shear strength parameters on stress state, Cabarkapa et al. adopt a Hvorslevtype approach using a hyperbolic function. They show substantial disagreement between their calculated values and the measured shear strength data reported in the paper. The only logical conclusion that we could derive from this discussion is that the approach adopted by the discussers is not applicable to the experimental data presented in the paper. Indeed, the errors in Fig. 7 are entirely reflective of the way the shear strength values are calculated by the discussers, and have no bearing on the appropriateness or otherwise of the effective stress function proposed. This is particularly the case noting that, in Fig. 7, the calculated errors are substantial only at suction values below the air entry value, in which $\chi=1$, and the mechanics of saturated soils should apply.

\section{REFERENCES}

Atkinson, J. H. \& Farar, D. M. (1985). Stress path tests to measure soil strength parameters for shallow slips. Proc. 11th Int. Conf. Soil Mech. Found. Engng San Francisco 2, 983-986.

Cabarkapa, Z., Cuccovillo, T. \& Gunn, M. (1998). A new triaxial apparatus for testing unsaturated soils. Proc. 2nd Int. Conf. Unsaturated Soils, Beijing (in press).

Khalili, N. (1998). Personal communication.

Maksimovic, M. (1996). A family of nonlinear failure envelopes for non-cemented soils and rock discontinuities, EJGE, ppr9607.

Wood, D. M. (1990). Soil behaviour and critical state soil mechanics, pp. 188-207. Cambridge University Press.

NOTE

The first part of this discussion was published in Géotechnique, 51, No. 5, 477-478, this now completes the correspondence. 